\title{
Extensive intrathoracic and intraperitoneal splenosis mimicking mesothelioma: a case report
}

\author{
Bandik Föh ${ }^{1,2^{*}} \mathbb{C}$, Malte Maria Sieren ${ }^{3}$, Marcus Both ${ }^{4}$, Marcus Seeger $^{5}$ and Rainer Günther ${ }^{5}$
}

\begin{abstract}
Background: Splenosis is the heterotopic autotransplantation of splenic tissue after severe splenic trauma and/ or splenectomy. The epidemiology is elusive, but splenosis is frequently misdiagnosed as malignant tumors of gastrointestinal, gynecological, or hematological origin before the correct diagnosis is ultimately found. We herein report a rare case of combined, extensive intraabdominal and intrathoracic splenosis initially presenting as pleural mesothelioma.
\end{abstract}

Case presentation: A 63-year-old Caucasian male presented with dyspnea and recurring thoracic pain. Initial X-ray and computed tomography scans showed disseminated intrathoracic and intraabdominal lesions. Consequently, thoracoabdominal mesothelioma or a polytopically metastasized cancer of unknown origin was suspected. A thorough examination of the patient's medical history and contrast-enhanced ultrasound by a skilled examiner revealed the diagnosis of extensive abdominal and thoracic splenosis as a consequence of an abdominal gunshot wound with a ruptured diaphragm several decades earlier. Timely diagnosis by noninvasive measures prevented the patient from potential complications of harmful diagnostic procedures, including nuclear imaging and biopsies. The patient is currently treated for hepatitis $C$ and chronic obstructive lung disease, whereas no specific treatment for splenosis is required.

Conclusions: We present a case of rare intrathoracic and intraperitoneal splenosis mimicking mesothelioma. Contrast-enhanced ultrasound and thorough patient history were used for diagnosis and prevented this patient from having to undergo potentially harmful diagnostics. Splenosis can occur after splenic trauma and, consequently, needs to be considered as a rare differential diagnosis to malignant tumors of various origins when a matching patient history is obtained.

Keywords: Benign tumors, Case report, Contrast-enhanced ultrasound, Mesothelioma, Splenosis

\section{Background}

Splenosis is the acquired heterotopic autotransplantation of splenic tissue [1]. It should not be confused with accessory spleens, which is a common, benign, congenital condition that occurs in $10-44 \%$ of autopsy cases

\section{*Correspondence: Bandik.Foeh@uksh.de}

${ }^{1}$ Medical Department I, University Hospital of Schleswig-Holstein, Building A, Ratzeburger Allee 160, 23562 Lübeck, Germany

Full list of author information is available at the end of the article without a specific medical history [1]. Splenosis, on the other hand, is a comparably rare condition that typically occurs after severe splenic trauma and/or splenectomy. Although its overall epidemiology remains largely unclear, it is reported in $26-76 \%$ of patients with a corresponding history of splenic trauma [2,3]. This divergence in case numbers is attributed to the rarely occurring symptoms that accompany the condition. Therefore, splenosis is mostly found incidentally after medical imaging reveals intraabdominal masses. Because splenosis give appropriate credit to the original author(s) and the source, provide a link to the Creative Commons licence, and indicate if changes were made. The images or other third party material in this article are included in the article's Creative Commons licence, unless indicated otherwise in a credit line to the material. If material is not included in the article's Creative Commons licence and your intended use is not permitted by statutory regulation or exceeds the permitted use, you will need to obtain permission directly from the copyright holder. To view a copy of this licence, visit http://creativecommons.org/licenses/by/4.0/. The Creative Commons Public Domain Dedication waiver (http://creativecommons.org/publicdomain/zero/1.0/) applies to the data made available in this article, unless otherwise stated in a credit line to the data. 
typically presents with multiple, ectopic, intraabdominal foci, it is frequently misdiagnosed as metastatic cancer of gastrointestinal, hepatic, pancreatic, renal, or gynecological origin, leading to additional and potential harmful diagnostics [4]. In rare cases, splenosis might occur intrathoracically and has thus been misinterpreted as thoracic lymphoma, thymoma, or mesothelioma [4]. To raise awareness for the possibility of disseminated splenosis mimicking cancer of various origins, and to prevent misdiagnosis, we herein report a rare case of combined intraabdominal and intrathoracic splenosis that was diagnosed without invasive diagnostic measures.

\section{Case presentation}

A 63-year-old Caucasian male presented to our hospital with mild dyspnea that had been present for years, and a recurring pain exacerbation in his left thoracic wall. His previous history included intravenous drug abuse, continued smoking for more than 30 years, and untreated hepatitis $C$ infection. When similar symptoms had occurred a few months previously, X-ray scans performed at another hospital showed suspicious masses at the left costal pleura. Therefore, pleural mesothelioma was considered. However, the patient was discharged and did not follow-up on this diagnosis before presenting to us.

After exclusion of myocardial ischemia, our X-ray scans showed the previously described lesions on the left costal pleura (Fig. 1). A subsequent contrast-enhanced computed tomography (CT) scan revealed two additional masses in the anterior mediastinum adjacent to the right atrium, measuring 2 and $4 \mathrm{~cm}$ in diameter (Fig. 2a, b) and recapitulated two lesions on the left costal wall measuring up to $5 \mathrm{~cm}$ in diameter (Fig. 2c). At this point, pleural mesothelioma, which had already been suspected elsewhere, was a plausible diagnosis.

However, multiple similar lesions were detected intraabdominally, whereas the spleen was missing (Fig. 3a). Specifically, two foci were found between the left diaphragm and the stomach $(5.6 \times 3.8 \mathrm{~cm}$ and $4.6 \times 2.6 \mathrm{~cm}$, Fig. 3b, c), between the liver and abdominal wall $(4.1 \times 1.7 \mathrm{~cm}$, Fig. $3 \mathrm{~d})$, and in the small pelvic cavity next to the $M$. iliopsoas sinister $(3 \mathrm{~cm}$ in diameter, Fig. 3e), among others. Curiously, the patient had to his knowledge never worked in an asbestos-polluted environment and the $\mathrm{CT}$ scans did not show any pleural effusions, which would typically be expected for mesothelioma [5]. Furthermore, the presence of abdominal masses is a possible, but not a common condition in mesothelioma [6]. Therefore, we considered a diagnostic biopsy to determine whether the lesions were metastases of a cancer of unknown origin.

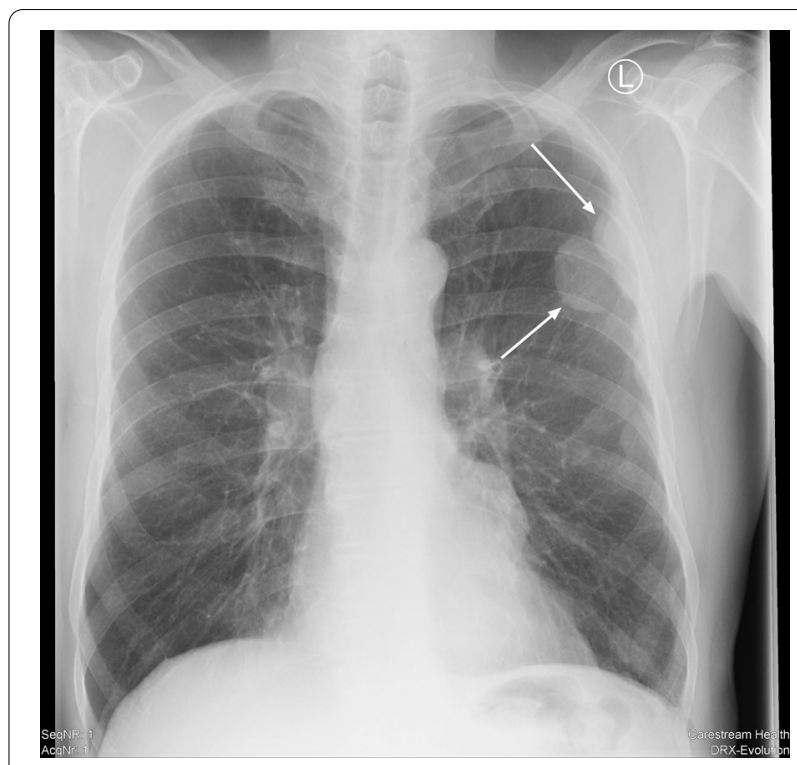

Fig. 1 Chest X-ray at admission. White arrows indicate pleural masses, initially interpreted as possible mesothelioma

However, we decided to first conduct an extensive interview with the patient that revealed an important, previously unknown part of his medical history: When asked for previous injuries, the patient remembered an incident in the early 1970s. At this time he had engaged in drug trafficking and got involved in an argument about a drug delivery that had not gone as planned. In the course of the argument, our patient suffered an abdominal gunshot wound with extensive injury. Unfortunately, there were no medical reports available from that time due to the patient very rarely visiting a doctor. However, the patient recalled that his spleen and diaphragm were severely damaged and needed surgical repair. Indeed, our CT scans showed that a splenectomy had been performed.

Instead of biopsy, we then utilized contrastenhanced ultrasound (CEUS) of the pleural and abdominal masses. On CEUS, a bolus of ultrasound contrast medium containing gas microbubbles is rapidly injected intravenously, followed by another bolus of saline solution for immediate dispersion via systemic circulation. When ultrasound waves are then directed at microbubbles flowing through the organ of interest, the compressible gas cores oscillate and show an increased echogenicity compared with surrounding tissue. Compared with other tissues, splenic tissue has the property to sequester microbubbles from circulation, causing an avid and persistent late-phase enhancement of up to 7 minutes after application, whereas malignant masses are characterized by early wash-out and late-phase hypoenhancement [7]. In our 

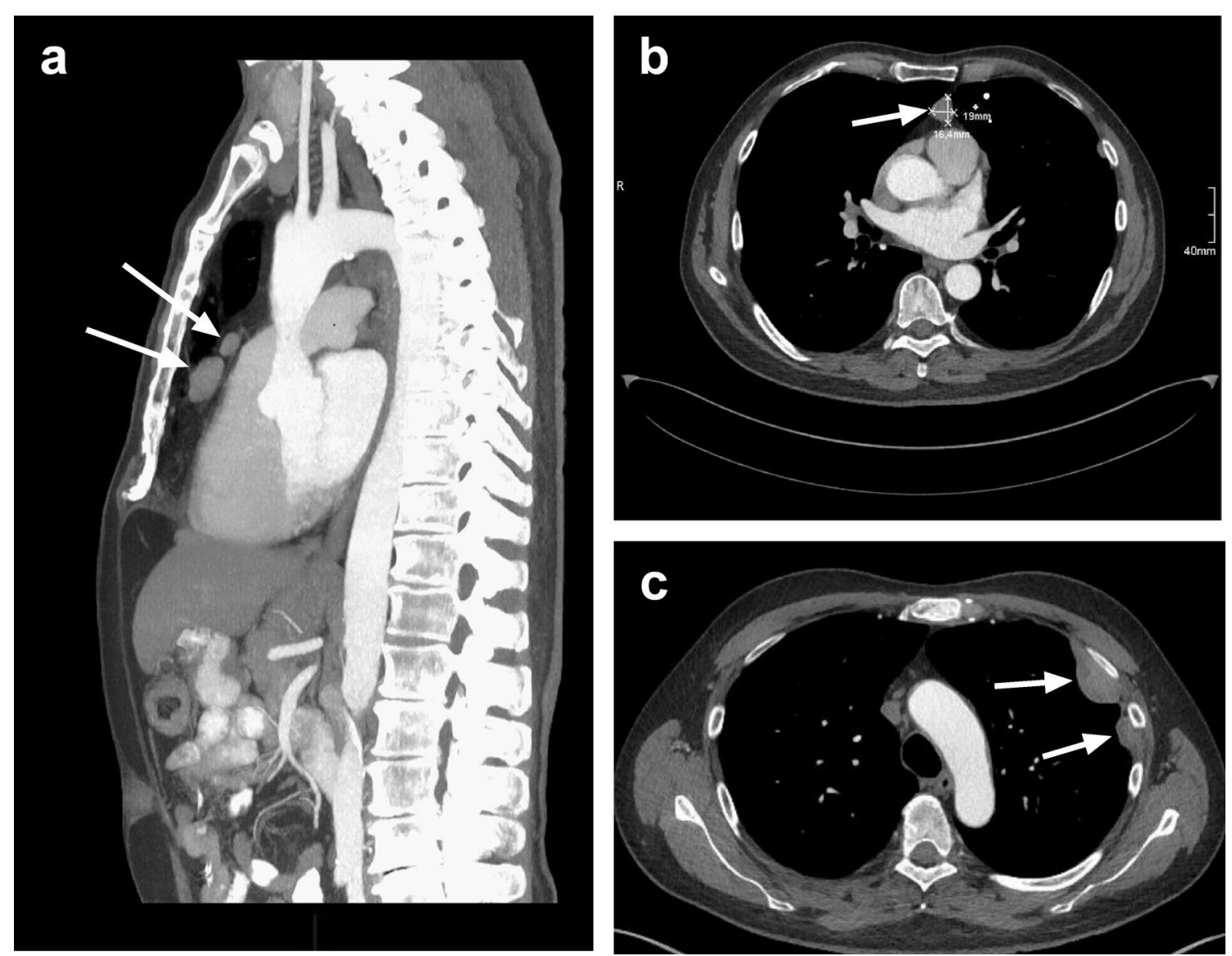

Fig. 2 Contrast-enhanced thoracic CT scan (arterial phase). Sagittal (a) and axial planes (b, c) of the thoracic cavity. White arrows indicate masses in the anterior mediastinum $(\mathbf{a}, \mathbf{b})$ and at the left costal pleura (c)

case, the application of sulfur hexafluoride microbubbles revealed circumscribed lesions that showed the characteristic pattern of splenic tissue, with persistent late-phase enhancement unlike malignant masses (Fig. 4a, b) [7]. Together with the very specific patient history and the medical imaging we performed, we were now convinced that we found the correct diagnosis and decided on a conservative approach without additional, invasive diagnostic measures. Follow-up examinations after 12 months showed no progress of the lesions, confirming the diagnosis of abdominal and thoracic splenosis based on detailed patient history and CEUS. Importantly, we were able to refrain from diagnostic biopsy, which otherwise might have led to serious complications considering the highly perfused splenotic tissue and the deranged coagulation due to hepatitis C-related liver dysfunction. Since splenosis is a benign condition, no specific treatment was necessary. Instead, treatment for hepatitis $C$ and chronic obstructive pulmonary disease was initiated to improve his prognosis and the patient received oral pain medication, which resolved his pleurisy.

\section{Discussion}

Due to its preferred occurrence in the abdominal cavity in up to $76 \%$ of severe splenic trauma requiring splenectomy [3], splenosis is most frequently confused with tumors of abdominal origin [4]. Rarely, and only after diaphragmatic damage, has thoracic splenosis been described $[8,9]$. As shown here, splenosis may present as disseminated intraabdominal and intrathoracic lesions resembling mesothelioma, advanced malignant tumors, or possibly echinococcosis. Splenotic lesions are usually located in body cavities or on the surface of intraabdominal or intrathoracic structures. However, very few cases of intraparenchymal splenosis have been described, and 

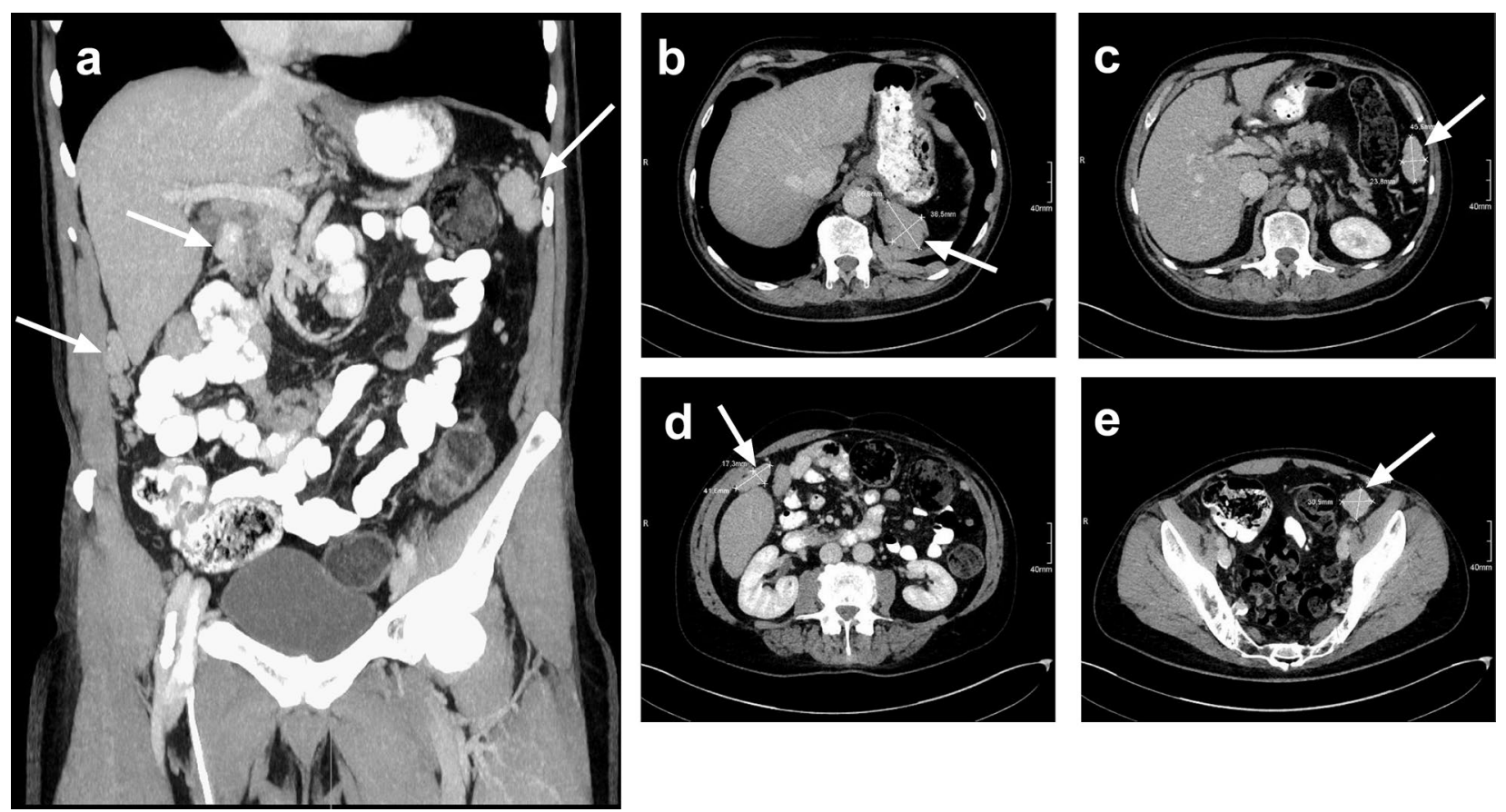

Fig. 3 Contrast-enhanced abdominal CT scan (portal phase). Coronal (a) and axial planes (b-e) of the abdominal and pelvic cavities. White arrows indicate masses under the left diaphragm (b, $\mathbf{c})$, between the abdominal wall and liver (d), and in the pelvic cavity (e)

are usually accompanied by preceding organ damage $[4,10,11]$. Common misdiagnoses of splenosis include intraabdominal lymphoma, hepatic, gastrointestinal or gynecological cancers, and endometriosis, and the consequences of misdiagnosis should not be underestimated.

The suspicion of a malignant tumor leads to stress for the patient and might cause a psychological burden, even when ultimately overturned. Moreover, diagnostic measures arising from the suspected diagnosis may lead to serious complications. The hemorrhagic potential of well-perfused and vulnerable splenotic masses is well documented by several case reports of spontaneous and posttraumatic bleeding in the peritoneal and thoracic cavities of patients with splenosis [12-15] implicating the necessity for careful evaluation of diagnostic biopsies to prevent complications. On the other hand, these considerations must never lead to delayed diagnosis of malignant tumors, since treatment at early stages leads to substantially improved outcomes compared with later stages. In our case, considering the deranged coagulation of our patient due to hepatitis C-related liver dysfunction, an attempted biopsy of one of the lesions might have led to severe bleeding. Additionally, nuclear imaging utilizing Tc-99m sulfur colloid or Tc-99m-tagged heat-damaged autologous erythrocytes are considered the gold standard to complete the diagnosis of splenosis, but have inherent risks due to radiation exposure.
We here want to emphasize the importance of detailed patient history and CEUS as a noninvasive and affordable diagnostic technique that can be used to confirm the diagnosis when performed by an experienced examiner. However, biopsy should be considered when the patient history does not include injury to the spleen of any kind since this seems to be a prerequisite for most cases of splenosis [2, 3]. Moreover, if follow-up imaging reveals progressive lesions, histological examinations are necessary since malignant tumors need to be ruled out.

\section{Conclusion}

We present a case of extensive intrathoracic and intraperitoneal splenosis mimicking malignant tumors in a patient that had suffered splenic trauma in the past. Suitable noninvasive diagnostic tools such as CT scans and CEUS performed by experienced examiners were used for diagnosis, and unnecessary invasive diagnostics were avoided. This case highlights that it is important to consider splenosis as a rare differential diagnosis for malignant tumors of the abdominal and thoracic cavities if there is a matching splenic trauma in the medical history. Thus, patients should be specifically asked for abdominal injuries and splenectomy in their medical history, even decades in the past. However, necessary diagnostics for malignant tumors must not be delayed, especially if 

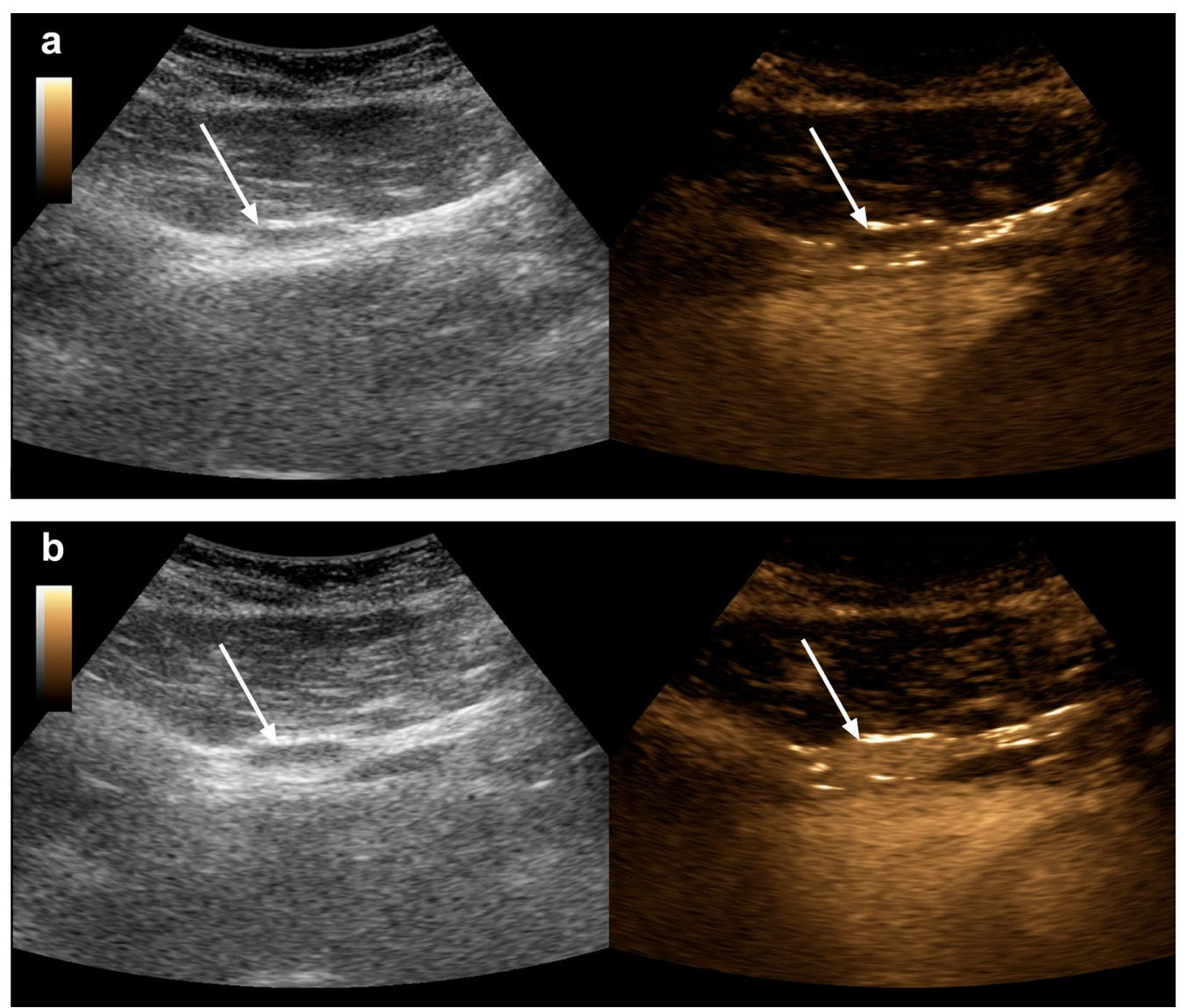

Fig. 4 Contrast-enhanced ultrasound of a splenotic lesion between abdominal wall and liver. Images are taken before (a) and during persistent (> 4 minutes) late-phase contrast enhancement typical for splenic tissue (b)

there is no typical history of splenic trauma or the lesions are progressive. Follow-up controls and, if necessary, nuclear imaging can be useful to ultimately confirm the diagnosis.

\section{Abbreviations}

CEUS: Contrast-enhanced ultrasound; CT: Computed tomography.

\section{Acknowledgements}

No additional acknowledgments.

\section{Authors' contributions}

All authors contributed to the concept and design. BF drafted the manuscript. $R G, M M S, M S$, and $M B$ contributed to critically revising the manuscript for important intellectual content. MB and MMS contributed radiologic images. MS contributed ultrasound images. All authors read and approved the final manuscript.

\section{Funding}

Open Access funding enabled and organized by Projekt DEAL.
Availability of data and materials Not applicable.

\section{Declarations}

Ethics approval and consent to participate Not applicable.

\section{Consent for publication}

Written informed consent was obtained from the patient for publication of this case report and any accompanying images. A copy of the written consent is available for review by the Editor-in-Chief of this journal.

\section{Competing interests}

The authors declare that they have no competing interests.

\section{Author details}

${ }^{1}$ Medical Department I, University Hospital of Schleswig-Holstein, Building A, Ratzeburger Allee 160, 23562 Lübeck, Germany. ${ }^{2}$ Institute of Nutritional Medicine, University of Lübeck, Ratzeburger Allee 160, 23562 Lübeck, Germany. ${ }^{3}$ Department of Radiology and Nuclear Medicine, University Hospital of Schleswig-Holstein, Ratzeburger Allee 160, 23562 Lübeck, Germany. ${ }^{4}$ Department of Radiology and Neuroradiology, University 
Hospital of Schleswig-Holstein, Arnold-Heller-Straße 3, 24105 Kiel, Germany. ${ }^{5}$ Hepatology Division, Department of Internal Medicine I, University Hospital of Schleswig-Holstein, Arnold-Heller-Straße 3, Bd. C, 24105 Kiel, Germany.

Received: 23 April 2021 Accepted: 21 January 2022

Published online: 19 February 2022

\section{References}

1. Fleming CR, Dickson ER, Harrison EG. Splenosis: autotransplantation of splenic tissue. Am J Med. 1976;61(3):414-9.

2. Livingston CD, Levine BA, Lecklitner ML, Sirinek KR. Incidence and function of residual splenic tissue following splenectomy for trauma in adults. Arch Surg. 1983;118(5):617-20.

3. Losanoff JE, Jones JW, Borzi P. Splenosis after laparoscopic splenectomy. Surg Endosc. 2001;15(12):1497-8.

4. Fremont RD, Rice TW. Splenosis: a review [Internet]. Vol. 100, Southern Medical Journal. South Med J; 2007 [accessed 2021 Apr 17]. p. 589-93. Available from: https://pubmed.ncbi.nlm.nih.gov/17591312/.

5. Mott FE. Mesothelioma: a review. Vol. 12, Ochsner Journal. Ochsner Clinic, L.L.C. and Alton Ochsner Medical Foundation; 2012. p. 70-9.

6. Kim J, Bhagwandin S, Labow DM. Malignant peritoneal mesothelioma: a review. Vol. 5, Annals of Translational Medicine. AME Publishing Company; 2017

7. Omar A, Freeman S. Contrast-enhanced ultrasound of the spleen. Vol. 24, Ultrasound. SAGE Publications Ltd; 2016. p. 41-9.

8. O'Connor JV, Brown CC, Thomas JK, Williams J, Wallsh E. Thoracic splenosis. Ann Thorac Surg. 1998;66(2):552-3.

9. Gopal K, Jones MT, Greaves SM. An unusual cause of chest pain. Chest. 2004;125(4):1536-8.

10. Sarda R, Sproat I, Kurtycz DF, Hafez R. Pulmonary parenchymal splenosis. Diagn Cytopathol. 2001;24(5):352-5.

11. Alaraj AM, Chamoun RB, Dahdaleh NS, Sfeir PM, Miski MS, Otrock ZK, et al. Thoracic splenosis mimicking thoracic schwannoma: case report and review of the literature. Surg Neurol. 2005;64(2):185-8.

12. Basile RM, Morales JM, Zupanec R. Splenosis: a cause of massive gastrointestinal hemorrhage. Arch Surg. 1989;124(9):1087-9.

13. Leitz EM, Kwan SW. Splenosis: a rare cause of gastrointestinal bleeding successfully treated with transarterial embolization. Clin J Gastroenterol. 2015;8(3):126-9.

14. Maki T, Omi M, Ishii D, Kaneko H, Misu K, Inomata H, et al. Spontaneous hemorrhage from splenic tissue 13 years after total splenectomy: report of a case. Surg Case Reports. 2015;1(1)

15. Sikov WM, Schiffman FJ, Weaver M, Dyckman J, Shulman R, Torgan P. Splenosis presenting as occult gastrointestinal bleeding. Am J Hematol. 2000;65(1):56-61.

\section{Publisher's Note}

Springer Nature remains neutral with regard to jurisdictional claims in published maps and institutional affiliations.

Ready to submit your research? Choose BMC and benefit from

- fast, convenient online submission

- thorough peer review by experienced researchers in your field

- rapid publication on acceptance

- support for research data, including large and complex data types

- gold Open Access which fosters wider collaboration and increased citations

- maximum visibility for your research: over $100 \mathrm{M}$ website views per year

At $\mathrm{BMC}$, research is always in progress.

Learn more biomedcentral.com/submissions 